\title{
Aprendizagem baseada em projetos e metodologia ágil: uma aplicação prática na Residência em Tecnologia da Informação na Justiça Federal
}

\author{
David M. Junior, Adelson L. de Oliveira, Isabel D. Nunes \\ Instituto Metrópole Digital - Universidade Federal do Rio Grande do Norte (UFRN) \\ Natal - RN - Brasil \\ davidjunior.info@gmail.com, adelsonlira2010@gmail.com, bel@imd.ufrn.br
}

Abstract. The application of a model that centralizes the student in the theoretical and practical framework of the disciplines and allows the application of their concepts through problem solving has been one of the great challenges of modern education. This article presents a proposal that links Project-Based Learning and Agile Methodologies of software development in a Post-Graduate course in Information Technology Residency applied to the Legal Area in Federal Justice. A proposal of management and monitoring of learning with technological tools and mapping of roles and processes.

Resumo. A aplicação de um modelo que centralize o aluno no arcabouço teórico e prático das disciplinas e permita a aplicação de seus conceitos através da resolução de problemas tem sido um dos grandes desafios da educação moderna. Este artigo traz uma proposta que une a Aprendizagem Baseada em Projetos e as Metodologias Ágeis de desenvolvimento de software em um curso de Pós-Graduação em Residência de Tecnologia da Informação aplicada à Área Jurídica na Justiça Federal. Uma proposta de gestão e acompanhamento de aprendizagem com ferramentas tecnológicas $e$ mapeamento de papéis e processos.

\section{Introdução}

No contexto da educação atual, é indiscutível a necessidade de ações e metodologias de aprendizagem para além do contexto tradicional e que estimulem nos indivíduos características fundamentais para seu desenvolvimento e destaque na sociedade. Fernandes et al. (2003) reforça que o aluno, agente principal no contexto dessas metodologias, ganha cada vez mais espaço nesse processo de construção associado ao "aprender fazendo".

Visando a aplicação dos aspectos teóricos em ambientes e projetos reais e com base neste novo cenário educacional surgiu o programa de Pós-Graduação em Residência em TI aplicado a Área Jurídica da Universidade Federal no Rio Grande do Norte (UFRN). Neste modelo de residência, os alunos absorvem em sala de aula os aspectos teóricos e podem executar projetos em Órgãos parceiros, como Tribunais ou Órgãos de controle. A residência conta com uma disciplina que acompanha o aluno durante sua atuação na Justiça Federal. A disciplina utiliza como metodologia 
VII Congresso Brasileiro de Informática na Educação (CBIE 2018)

Anais do XXIX Simpósio Brasileiro de Informática na Educação (SBIE 2018)

pedagógica a Aprendizagem Baseada em Projetos (ABP) [Bender, 2015], em que os alunos incorporam as necessidades de projetos reais.

Assim, o objetivo deste artigo é apresentar a disciplina de acompanhamento dos alunos que une a abordagem de Aprendizagem Baseada em Projetos e a utilização de Metodologias Ágeis [Foggetti, 2014] em projetos de infraestrutura, Business Intelligence (BI) e desenvolvimento de software.

\section{O programa de Pós-Graduação em Residência em TI aplicada à Área Jurídica}

O programa de Residência em Tecnologia da Informação aplicado à Área Jurídica, criado em 2017 é uma parceria da UFRN, através do Instituto Metrópole Digital, com diversos Órgãos e Tribunais. Nele os residentes devem incorporar o conhecimento adquirido em sala de aula na prática institucional do Órgão ou Tribunal em questão, através de pesquisa, inovação e desenvolvimento de novos produtos.

No caso da Justiça Federal no Rio Grande do Norte (JFRN), são 12 (doze) residentes com carga horária de 30 horas semanais, dividida em quatro dias por semana no Órgão, e um dia dedicado à aprendizagem teórica na Universidade, sendo a duração total de 18 (dezoito) meses. Na JFRN, divididos em três áreas de atuação, redes e infraestrutura, Business Intelligence e desenvolvimento de software, eles aplicam os conceitos e expertise em inovação, pesquisa e desenvolvimento de novas soluções na disciplina de ABP. Já na universidade as disciplinas são divididas em núcleo comum (com disciplinas de interesse a todas às áreas), núcleo de desenvolvimento de software e núcleo de redes e infraestrutura.

\section{A metodologia de captura e desenvolvimento dos projetos da ABP}

O processo de iniciação, desenvolvimento do projeto e análise do processo de aprendizagem e do produto gerado, segue ciclo adaptado do Scrum [Schwaber e Sutherland 2017], framework utilizado para gestão e acompanhamento de projetos ágeis, conforme detalhado na Figura 1.

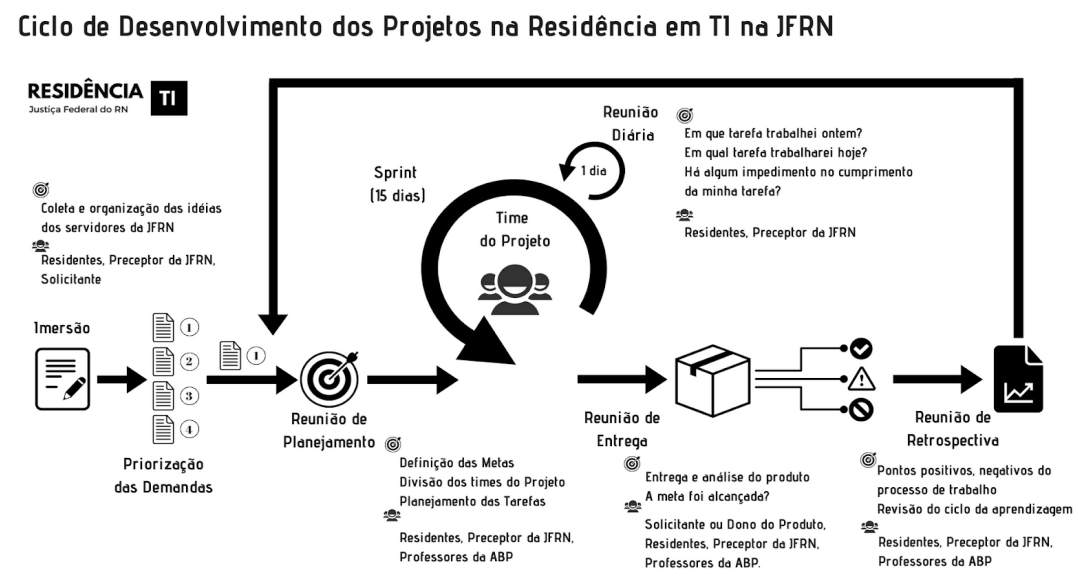

Figura 1. Ciclo de Desenvolvimento dos Projetos da Residência em TI na JFRN ${ }^{1}$

\footnotetext{
${ }^{1}$ Fonte: própria.
} 
VII Congresso Brasileiro de Informática na Educação (CBIE 2018)

Anais do XXIX Simpósio Brasileiro de Informática na Educação (SBIE 2018)

Ao receber uma solicitação de visita em ambientes da JFRN ou uma proposta de projeto, os residentes iniciam o processo de imersão. O objetivo é capturar uma ideia dada por servidores e magistrados da JFRN e aprimorar o seu conceito. Uma reunião é marcada com o servidor proponente para coletar informações mais apuradas relativas às suas necessidades e requisitos, e logo após é preenchido um documento denominado Ficha Inicial do Projeto. O documento procura trazer uma introdução e informações básicas e gerar interesse nos alunos, trazendo à tona o conceito de âncora na ABP [Bender, 2015].

A gestão da JFRN então recebe o documento e analisa a relevância e o impacto da execução desse projeto, priorizando seu desenvolvimento de acordo com os parâmetros estratégicos da instituição. Com a demanda definida, é realizada a Reunião de Planejamento. Essa reunião tem uma duração média de uma hora e tem como objetivos principais a definição da meta a ser alcançada no processo de desenvolvimento, a definição do time que irá trabalhar no projeto, e o detalhamento das tarefas a serem realizadas durante a Sprint.

Com os projetos priorizados e as metas definidas, os residentes se voluntariam para formar os times para trabalhar com o projeto com o qual mais se identificaram e mais se sentiram motivados, iniciando o processo de inovação e investigação para promover solução ao desafio proposto.

O time de projeto, agora empenhado em entregar o que foi definido na meta, realiza suas tarefas e inicia a Sprint, com duração média de 15 dias. O time deve realizar Reuniões Diárias em um horário específico do dia com o objetivo de responder três perguntas básicas: o que foi feito pelo residente até o momento, em que ele estará trabalhando nas próximas horas e se há algum impedimento que atrapalha o desenvolvimento da sua tarefa no momento. Essa reunião tem uma duração média de dez minutos e tem como escopo central integrar o time e compartilhar as atividades para que não haja conflito ou execução da mesma atividade por parte de dois ou mais residentes.

Ao final da Sprint, acontece a Reunião de Entrega. Com uma duração média de uma hora, dela participam os requerentes, o preceptor da JFRN, os professores da disciplina de $\mathrm{ABP}$ e os residentes. Estes últimos elaboram apresentação das entregas definidas na Reunião de Planejamento, identificando se a meta foi atingida ou não. No processo de avaliação do produto, o requerente ou dono do produto (Product Owner), define se a entrega foi aceita sem ressalvas, aceita com ressalvas ou rejeitada. Caso seja aceito sem ressalvas o produto é aplicado em produção e logo utilizado pelo usuário em seu setor, se aceito com ressalvas ou rejeitado, são incrementadas novas atividades ao projeto que serão priorizadas em uma nova Reunião de Planejamento e desenvolvidas em uma nova Sprint. Na sequência, inicia-se uma análise do trabalho realizado e uma discussão de pontos positivos, negativos ou dúvidas que surgiram no desenvolvimento dos projetos, tudo isso na Reunião de Retrospectiva. Com duração de uma hora e com a participação dos professores, residentes e preceptor da JFRN, a reunião promove reflexão para melhoria do trabalho nos desafios vindouros.

A ABP traz como característica o dinamismo, motivação dos alunos e aumento do desempenho acadêmico. A união de tais características que acompanham os alunos durante o desenvolvimento dos projetos, sob orientação dos professores responsáveis e 
VII Congresso Brasileiro de Informática na Educação (CBIE 2018)

Anais do XXIX Simpósio Brasileiro de Informática na Educação (SBIE 2018)

dos aspectos inerentes às metodologias ágeis mostram o aumento da performance dos alunos residentes. Além disso, para que o fluxo de trabalho e todo o processo possa deixar um histórico, utiliza-se um suporte da tecnologia da informação e comunicação permeando todo o ciclo metodológico, tais como ferramentas para captura, integração e organização do trabalho desempenhado pelos residentes.

\section{Resultado da aplicação da metodologia em um Projeto}

Recebido no portal da Residência, o projeto Botão do Pânico foi uma necessidade elencada pelos magistrados da instituição. Visando acionar o grupo de segurança institucional de uma forma mais célere e promover melhoria na segurança institucional, o grupo de residentes iniciou o processo de investigação e pesquisa para prover a melhor solução.

Uma reunião inicial de coleta de requisitos, preconizada pelo processo de imersão, foi realizada com o idealizador do projeto. Preenchida a Ficha Inicial de Projeto, foi priorizado pela gestão e entrou no ciclo de desenvolvimento dos residentes. A Reunião de Planejamento definiu a meta e o time do projeto. Na sequência o time do projeto elencou as atividades que seriam necessárias para o cumprimento da meta no $\mathrm{GitLab}^{2}$. Ao término da Sprint ocorreu a Reunião de Entrega (Figura 2). O produto final recebeu algumas recomendações que seriam executadas em um segundo ciclo, mas foi aceito sem ressalvas.

Após a entrega, foi realizada a Reunião de Retrospectiva, avaliando os pontos positivos, negativos e algumas questões do projeto ou ainda questões acadêmicas.

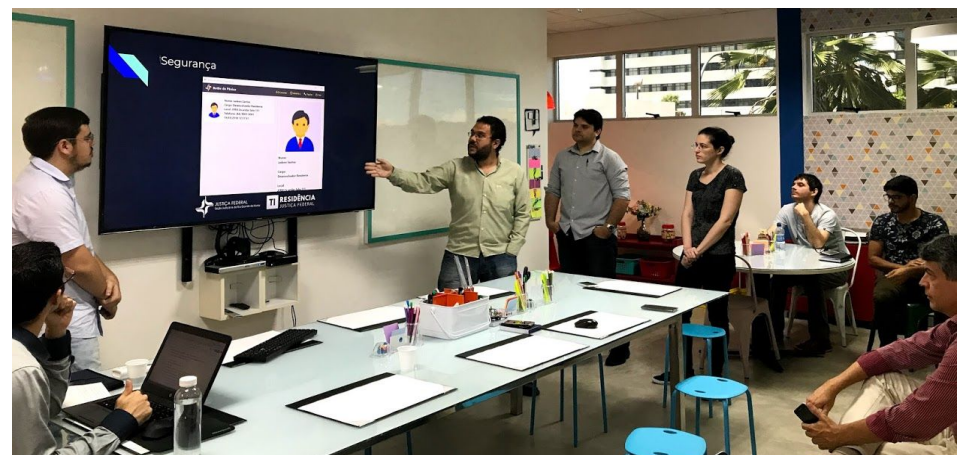

Figura 2. Reunião de Entrega do Sistema Botão do Pânico ${ }^{3}$

O ciclo teve duração de 21 (vinte um) dias e desenvolveu algumas habilidades nos residentes como: coleta e documentação de requisitos, programação na Linguagem de desenvolvimento $\mathrm{Java}^{4}$, conceitos básicos em Redes de Computadores e comunicação interpessoal.

As reuniões são acompanhadas, tanto pelo time responsável pelo projeto, quanto pelos professores da disciplina de ABP e líderes da JFRN. Desta forma, não somente o projeto é realizado, como principalmente, os professores são capazes de identificar a influência das disciplinas ministradas nas tarefas e entregas realizadas pelos residentes.

\footnotetext{
${ }^{2}$ https://about.gitlab.com/

${ }^{3}$ Fonte: própria.

${ }^{4}$ https://go.java/index.html
} 
VII Congresso Brasileiro de Informática na Educação (CBIE 2018)

Anais do XXIX Simpósio Brasileiro de Informática na Educação (SBIE 2018)

\section{Conclusão}

O Programa de Residência em Tecnologia da Informação aplicada à Área Jurídica é uma proposta inovadora na construção de um profissional com práticas de negócio e amplo conhecimento teórico aplicado em problemas de casos reais. A disciplina de Aprendizagem Baseada em Projetos traz essa perspectiva de, através das necessidades do Órgão, mergulhar o residente na resolução de problemas ou ainda promover melhoria no processo de trabalho dos servidores através do aporte e conhecimento tecnológico.

Observa-se ainda que a metodologia de trabalho pensada na Justiça Federal para essa disciplina tem promovido o trabalho colaborativo, as discussões em reuniões, além de sustentar o trabalho dos professores no processo avaliativo dos alunos, identificando habilidades interpessoais, características que podem ser potencializadas e inserindo o aluno em um contexto de trabalho real, alinhando a prática aos conceitos abordados em sala de aula. O processo elaborado está sendo avaliado pelos residentes através da aplicação de questionário que deverá ser aplicado ao término de cada Sprint, como parte integrante da Reunião de Retrospectiva.

O reconhecimento do trabalho fica evidente com as premiações associadas a este programa e sua metodologia no III Prêmio AJUFE de Boas Práticas do Judiciário.

\section{Referências Bibliográficas}

Bender, W. N. Aprendizagem baseada em projetos: educação diferenciada para o século XXI. Porto Alegre: Penso, 2015.

Brito, M. C. A.; Silva, F. P.; Cabral, E. P. (2013) "Elaboração de uma metodologia de desenvolvimento de software em uma instituição de ensino". Revista Brasileira de Informática na Educação (RBIE), v. 21, n. 02, p. 52.

Fernandes, J.D. et al. Estratégias para a implantação de uma nova proposta pedagógica na escola de enfermagem da Universidade Federal da Bahia. Rev Bras Enferm, v. 56, n. 4, p. 392-5, 2003.

Foggetti, Cristiano (Org.). Gestão Ágil de Projetos. Coleção Bibliográfica Universidade Pearson. São Paulo: Education do Brasil, 2014.

Oliveira, E. W.; Borges, M.; Silva, W. Uma Proposta de Framework para Apoiar o Planejamento de Trabalhos em Grupo Baseados em Project Based Learning. VI Congresso Brasileiro de Informática na Educação (CBIE 2017). Anais do SBIE 2017, p. 486-495.

Schwaber, K,; Sutherland J. Guia do Scrum: Um guia definitivo para o Scrum: As regras do jogo. Scrum Guides. 2017. Disponível em: https://www.scrumguides.org/docs/scrumguide/v2017/2017-Scrum-Guide-Portuguese-E uropean.pdf Acesso em 25 de março de 2018. 